\title{
Melanosis Coli - An Atypical Presentation
}

\author{
HAM NAZMUL AHASAN, ${ }^{1}$ MOHAMMAD ASHIKIMRAN KHAN, ${ }^{2}$ MD. SHAHRIAR MAHBUB, ${ }^{2}$ MD. BILLALALAM, ${ }^{3}$ MD. \\ TITU MI AH, ${ }^{4}$ RATAN DAS GUPTA, ${ }^{4}$ KHAN MOHAMMAD ARI F ${ }^{5}$
}

\begin{abstract}
Melanosis Coli is described as black or brown discoloration of the mucosa of the colon. It is a benign condition, which arises from anthraquinone laxative abuse and usually has no symptoms of its own. Though not a very rare condition, to the best of our knowledge, no case has been reported on melanosis coli in Bangladesh. Here we report a case of middle aged lady presenting with passage of blood mixed stool for one year. Colonoscopy was performed which revealed melanosis coli and which was later confirmed by histopathology. Not thought to be a pre malignant condition, it has been found in some patients with other diseases.
\end{abstract}

Keyword: Melanosis coli, Anthraquinone, Lipofuscin, Laxative, Bangladesh

\section{Introduction}

The term melanosis coli was initially proposed by Virchow. ${ }^{1}$ "Melanosis" is a Greek word denoting any condition characterized by abnormal dark coloration of skin or mucosa. Melanosis, by definition, can be due not only to the deposition of melanin, but of other dark-pigmented granules, such as hemosiderin, lipofuscin, lipofuscin- like pigment or ferrum sulfate as well. The disease itself usually cause no symptoms. ${ }^{2,}{ }^{3}$ In a few cases, while investigating patients with lower gastrointestinal tract bleeding, melanosis coli has been found as an incidental finding. ${ }^{4}$ A small study suggested the possibility of association of chronic colitis with melanosis coli. ${ }^{5}$ Our lady presented with passage of blood mixed stool and even after thorough investigation no other definite pathology was detected. Presentation of melanosis coli with passage of blood mixed stool is atypical, is yet to be reported in our country. So we report this case with the view to promote further studies on the disease entity in our country's perspective.

\section{Case Report}

A 40 year old lady presented with complaints of increased frequency of bowel movement for one and half years, passage of blood mixed stool for one year and occasional melaena . Further inquiry revealed her stool was occasionally frothy and mucus mixed. She complained of no change of appetite, loss of weight, abdominal pain, tenesmus. She is asthmatic since childhood (poorly controlled), hypertensive for last 8 years (controlled on regular medication). Drug history revealed she has been using oral contraceptive pill for last 25 years, and a herbal medicine for the last 4 years for her bronchial asthma. She has no family history of colonic carcinoma, no joint pain, visual complaints or skin rash.

Clinical examination revealed she was mildly anaemic, pulse rate-92/min, blood pressure-140/80mm of Hg. Her alimentary system examination was normal. Her respiratory system examination revealed a few expiratory rhonchi. Laboratory investigation showed her Hb-9.0 gm/dl, ESR- $25 \mathrm{~mm}$ in $1^{\text {st }}$ hour. Peripheral blood film showed microcytic hypochromic anaemia. Stool occult blood test was positive.

Her colonoscopy revealed mucosa of the whole colon is pigmented. Histopathology of colonic tissue showed multiple fragments of inflamed large bowel mucosae with pigment laden macrophages in the lamina propria with infiltration of inflammatory cells - features which are compatible with melanosis coli.

We discharged the patient with advice of discontinuing the herbal medication and a follow up visit.

1. Professor, Department of Medicine, Dhaka Medical College

2. Post-graduate trainee, Department of Medicine, Dhaka Medical College

3. Associate Professor, Department of Medicine, Dhaka Medical College

4. Assistant Professor, Department of Medicine, Dhaka Medical College

5. Indoor Medical Officer, Department of Medicine, Dhaka Medical College

Correspondence: Dr. Mohammad Ashik Imran Khan, Post Graduate Trainee, Dhaka Medical College Hospital, Dhaka. E Mail: ashikmrn@yahoo.com 


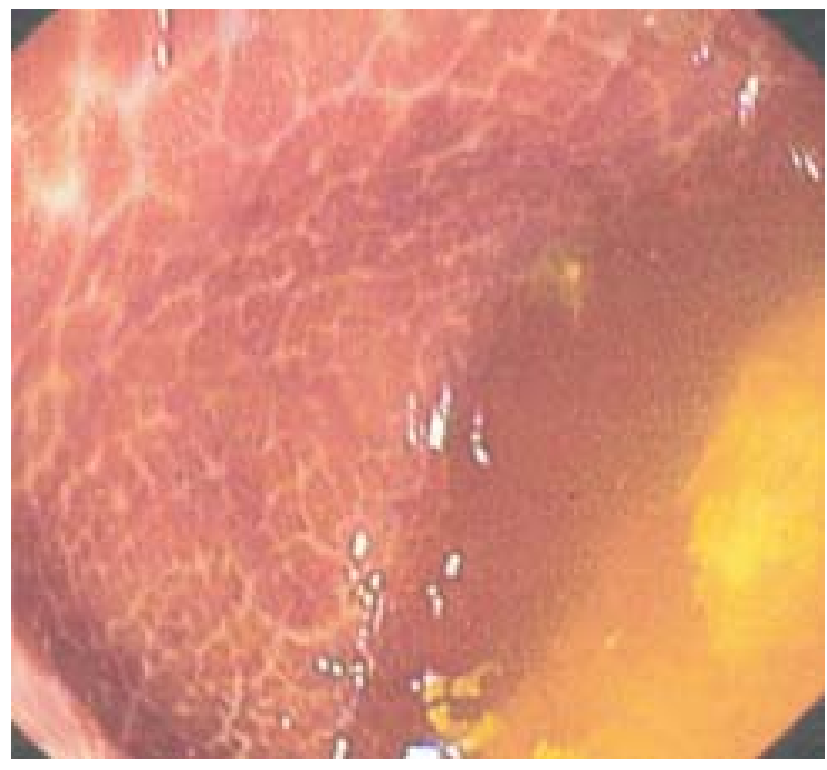

Fig.-1A

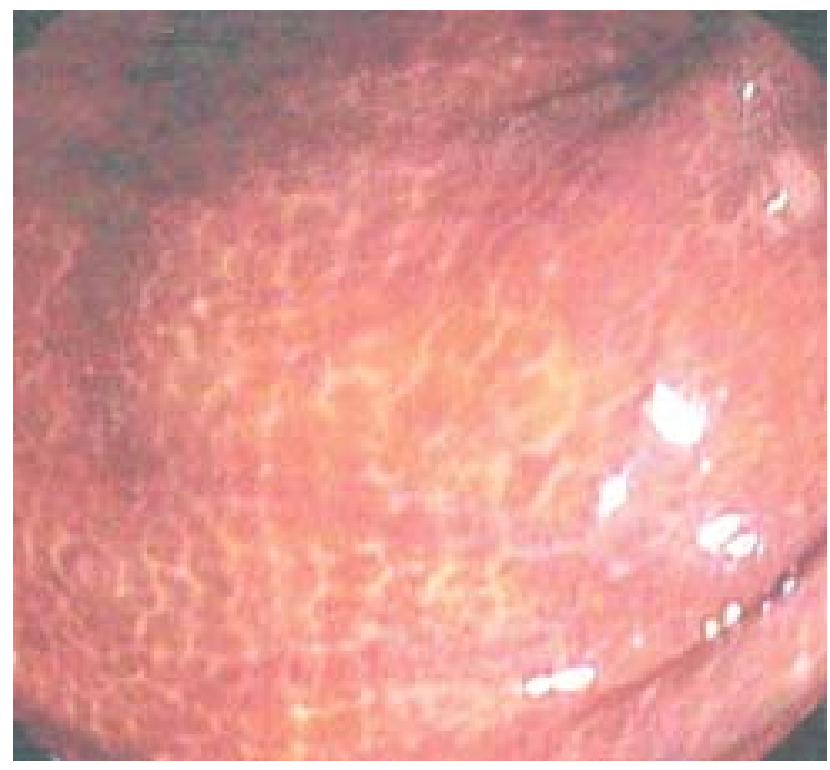

Fig-1B

Fig.-1: Various parts of colon showing diffuse pigmentation (Fig-1A - Caecum, Fig.-1B-Ascending colon)

\section{Discussion}

Melanosis coli was first described by Cruveilhier's about 150 years back. Virchow gave the name melanosis coli to the condition, the first sigmoidoscopic appearance being described by Pick in 1911. ${ }^{1-3,6}$ Melanosis coli occurs because of the deposition of a brown black pigment called lipofuscin in the lamina propria of the colon. The initial event is mucosal cell death or apoptosis resulting from anthraquinone laxative abuse. These cells are then phagocytosed by macrophages in lamina propria producing lipofuscin, which gives a dark colour to the colonic mucosa.$^{7}$ A variable incidence of melanosis coli has been reported in various studies with some studies reporting it in well over $50 \%$ of the patients. The wide variance probably is because some papers have only looked at macroscopic while others have reported both microscopic and macroscopic melanosis coli. Its incidence is higher in older population and people who suffer from conditions like irritable bowel syndrome and chronic constipation possibly because of the rising popularity of the herbal remedies containing anthraquinones . The average time for appearance of melanosis using anthracene derivatives is approximately 12 months. It usually disappears 4 to 12 months after discontinuing the drugs . ${ }^{8,9}$ However, melanosis coli has also been found in patients who do not use laxatives or suffer from constipation, possibly because of the apoptosis of epithelial cells and their subsequent phagocytosis by macrophages of lamina propria with accumulation of lipofuscin pigment. There are good reasons for not considering melanosis coli as a reliable marker of chronic anthranoid laxative use as only $73.4 \%$ of patients with melanosis coli admitted to anthranoid use. 10 Furthermore, anthranoids are also found in some preparations of liver drugs, digestives, or alternative herbal remedies.$^{11}$ In melanosis coli, the pigmentation usually doesn't affect the small bowel but cases have been reported where it affected small bowel. ${ }^{12}$ Though melanosis coli is usually asymptomatic ,our patient presented with passage of blood mixed stool for more than a year without any evidence of any other gastrointestinal pathology which were ruled out by investigations. Some patients presenting with lower gastrointestinal bleeding were found to have melanosis coli while some other causative factor was always present. ${ }^{4} \mathrm{~A}$ study involving small number of patients with inflammatory bowel disease showed that those with disease duration of at least seven years had melanosis coli suggesting that chronic colitis could cause melanosis coli even in the absence of laxative use. ${ }^{5}$ We would like to suggest that our patients symptoms were more likely due to melanosis coli as her clinical and laboratory parameters were in favour of it. . In our case the most likely cause was of melanosis was the herbal medicine which our patient has been using for her poorly controlled bronchial asthma for the last four years. Regarding the associations between the use of laxatives, melanosis coli, and colonic adenocarcinoma, conflicting evicence is present where as some studies show increased incidence of colorectal adenomas in melanosis coli. In some reports, the development of tubulovillous adenoma with high-grade dysplasia was described in a patient who took an over-the-counter anthranoid-containing laxative . But some other studies showed neither anthranoid laxative use, 
even in the long term, nor macroscopic or marked microscopic melanosis coli were associated with any significant risk for the development of colorectal adenoma or carcinoma. ${ }^{12-14}$

In conclusion we can say that melanosis coli though not proven to be a pre malignant condition till date, further studies are required to give a conclusive ending to the debate regarding its presenting features, association, and their implications.

\section{Conflict of Interest: None}

\section{References}

1. Virchow R.[Archives of Pathological Anatomy and Physiology and of Clinical Medicine], 1847; 1, 379. German.

2. Banai J, Fenyvesi A, Gonda G, Petö I. Melanosis jejuni. Gastrointest Endosc 1997, 45:834-840

3. Rosai J. Rosai and Ackerman's Surgical Pathology. 9th edition. Mosby: New York, 2004

4. Rees W D, Bancewicz J. Endoscopic diagnosis of a bleeding ileal carcinoid Tumour . Gut 1984; 25: 211-212

5. Pardi DS, Tremaine WJ, Rothenberg HJ, Batts KP. J Clin Gastrenterol 1998; 26(3):167-70.

6. Pick, L.[Ueber die Melanose der Dickdarmschleim haut.] Berliner Klinische Wochenschrift, 1911; 19, 840. German

7. Walker NI, Bennett RE, Axelsen RA: Melanosis coli. A consequence of anthraquinone induced apoptosisof colonic epithelial cells. Am J Pathol 1988; 131(3):465-466.
8 Kostela E, Kulju T, Collan Y. Melanosis coli, prevalence, distribution and histological features in 200 consecutive autopsies at Kuopio University Central Hospital. Dis Colon Rectum 1989; 32(3):235-9.

9. Wittoesch JH, Jackman RJ, McDonald JR: Melanosis coli. General review and a study of 887 cases. Dis Colon Rectum 1958; 1:172-80.

10. Byers RJ, Marsh P, Parkinson D, Haboubi NY. Melanosis coli is associated with an increase in colonic epithelial apoptosis and not with laxative use. Histopathology. 1997;30: 160-164.

11. Bertram PD. Melanosis coli: a consequence of "alternative therapy” for psoriasis.Am J Gastroenterol 1993;88:971

12. Won KH, Ramchand S. Melanosis of the ileum. Case report and electron microscopic study. Am J Dig Dis 1970; 15: 5764

13. Nusko G, Schneider B, Ernst H, Wittekind C, Hahn EG. Melanosis coli: a harmless pigmentation or a precancerous condition? Z Gastroenterol 1997; 35: 313-318

14. Nusko G, Schneider B, Schneider I, Wittekind C, Hahn EG. Anthranoid laxative use is not a risk factor for colorectal neoplasia: results of a prospective case control study. Gut 2000; 46:651-655

15. Nascimbeni R, Donato F, Ghirardi M, Mariani P, Villanacci V, Salerni B. Constipation, anthranoid laxatives, melanosis coli, and colon cancer: a risk assessment using aberrant crypt foci. Cancer Epidemiol Biomarkers Prev. 2002; 11: 753757. 